\title{
Article/Artigo
}

\section{Antimicrobial use and incidence of multidrug-resistant Pseudomonas aeruginosa in a teaching hospital: an ecological approach}

\author{
Uso de antimicrobianos e incidência de Pseudomonas aeruginosa multidroga-resistente em um \\ hospital de ensino: uma abordagem ecológica
}

\author{
Mariana Tresoldi das Neves ${ }^{1}$, Mariana Eliza Pinto de Lorenzo ${ }^{1}$, Ricardo Augusto Monteiro Barros Almeida \\ and Carlos Magno Castelo Branco Fortaleza ${ }^{1,2}$
}

\begin{abstract}
Introduction: Multidrug-resistant Pseudomonas aeruginosa is a major threat in healthcare settings. The use of antimicrobials can influence the incidence of resistant strains by direct and indirect mechanisms. The latter can be addressed by ecological studies. Methods: Our group attempted to analyze the relation between the use of antipseudomonal drugs and the incidence of MDR-PA among 18 units from a 400-bed teaching hospital. The study had a retrospective, ecological design, comprising data from 2004 and 2005. Data on the use of four antimicrobials (amikacin, ciprofloxacin, ceftazidime and imipenem) were tested for correlation with the incidence of MDR-PA (defined as isolates resistant to the four antimicrobials of interest) in clinical cultures. Univariate and multivariate linear regression analyses were performed. Results: Significant correlations were determined between use and resistance for all antimicrobials in the univariate analysis: amikacin (standardized correlation coefficient $=0.73$, $\mathrm{p}=0.001)$; ciprofloxacin $(0.71, \mathrm{p}=0.001)$; ceftazidime $(0.61, \mathrm{p}=0.007)$ and imipenem $(0.87$, $\mathrm{p}<0.001)$. In multivariate analysis, only imipenem $(0.67, \mathrm{p}=0.01)$ was independently related to the incidence of multidrug-resistant strains. Conclusions: These findings share similarities with those reported in individual-based observational studies, with possible implications for infection control.
\end{abstract}

Key-words: Pseudomonas aeruginosa. Antimicrobial resistance. Ecological study.

\section{RESUMO}

Introdução: Pseudomonas aeruginosa multirresistente é uma grande ameaça a pacientes nos serviços de saúde. $\mathrm{O}$ uso de antimicrobianos pode influenciar a incidência de isolados resistentes por mecanismos diretos e indiretos. Estudos ecológicos são indicados para avaliação conjunta desses mecanismos. Métodos: Foi analisada a relação entre o uso de antimicrobianos antipseudomonas e a incidência de PAMR em 18 unidades de um hospital de 400 leitos. O estudo teve delineamento ecológico retrospectivo, abordando dados dos anos de 2004 e 2005. Dados sobre uso de quatro antimicrobianos (amicacina, ciprofloxaxina, ceftazidima e imipenem) foram testados para correlação com a incidência de PAMR (resistente aos quatro antimicrobianos de interesse). Análises univariadas e multivariadas foram realizadas por regressão linear. Resultados: $\mathrm{Na}$ análise univarida, foram encontradas correlações significantes entre uso e resistência para os quatro antimicrobianos testados: amicacina (coeficiente de correlação padronizado $=0,73 ; \mathrm{p}=0,001)$, ciprofloxacina $(0,71 ; \mathrm{p}=0,001)$, ceftazidima $(0,61 ; \mathrm{p}=0,007)$ e imipenem $(0,87, \mathrm{p}<0,001)$. Na análise univariada, somente imipenem $(0,67 ; \mathrm{p}=0,01)$ foi relacionado de forma indepentente à incidência de PAMR. Conclusões: Esses achados apresentam semelhanças com outros obtidos em estudos observacionais de base individual, e têm implicância práticas para o controle de infecção em hospitais.

Palavras-chaves: Pseudomonas aeruginosa. Resistência antimicrobiana. Estudo ecológico.

1. Department of Tropical Diseases, Botucatu School of Medicine, São Paulo State University, Botucatu, SP, Brazil. 2. Bauru State Hospital, Botucatu School of Medicine, São Paulo State University, Bauru, SP, Brazil. Address to: Dr. Carlos Magno Castelo Branco Fortaleza. Dept ${ }^{\circ}$ Doenças Tropicais e Diagnóstico por Imagem/FMB/UNESP. Distrito de Rubião Júnior, 18618-970 Botucatu, SP, Brazil.

Phone: 5514 3811-6212; Fax: 55 14 3815-9898

e-mail: cmfortaleza@uol.com.br

Received in 15/08/2010

Accepted in 15/09/2010

\section{INTRODUCTION}

Recent reports from microbiological surveillance systems documented a worrisome increase in the incidence ofmultidrug-resistantPseudomonas aeruginosa (MDR-PA) in acute care hospitals ${ }^{1,2}$. These findings have been attributed to the complexity and invasiveness of medical procedures, as well as to the failure to implement barrier strategies. However, it is reasonable to believe that there is some contribution from indiscriminate use of high-spectrum antimicrobials ${ }^{3}$.

The arsenal of antipseudomonal drugs comprises few options. Amikacin, ciprofloxacin, ceftazidime and imipenem are among the antimicrobials with some activity against $P$. aeruginosa strains. They are also widely used in hospital settings. An interesting question is to what extent the use of these agents is responsible for the emergence and spread of MDR-PA.

Observational studies have been used to analyze the relation between antimicrobial use and resistance in P. aeruginosa. Most of these studies assess individual risk factors using case-control designs ${ }^{4-6}$. However, the spread of multidrug-resistant pathogens is the result of several factors that act directly or in indirectly on individuals at risk. This is a sound argument for conducting studies using an ecological approach ${ }^{7}$.

The objective of the present study was to investigate correlations between the aggregate use of antipseudomonal drugs and the incidence of MDRPA among several units from a teaching hospital.

\section{METHODS}

\section{Setting}

The study was conducted in the Clinics Hospital of the Botucatu Faculty of Medicine of São Paulo State University (UNESP). This is a teaching hospital with 400 active beds that serves an area of approximately one million inhabitants. 


\section{Study design}

An ecological design was used for comparing rates of antimicrobial use and incidence of resistant $P$. aeruginosa in 18 units that admit adult patients. A unit was defined as a contiguous area with several rooms for inpatients sharing the same medical and nursing staff. Neonatal and pediatric units, as well as emergency rooms and outpatients clinics, were excluded from the study.

Data were retrospectively collected in the hospital pharmacy and in the microbiology laboratory databases. The study period comprised the years 2004 and 2005.

This study focused on the use of four antimicrobials with antipseudomonal activity: amikacin, ciprofloxacin, ceftazidime and imipenem. Their use was determined among hospital units using the anatomical therapeutic chemical/defined daily dose (ATC/DDD) system ${ }^{8}$. Results were expressed in number of DDD per 1,000 patients-day.

Disk diffusion tests for antimicrobial susceptibility were routinely performed in the microbiology laboratory, according to the standards of the Clinical and Laboratory Standards Institute (formerly the National Committee for Clinical Laboratory Standards) ${ }^{9}$. MDR-PA was defined as any isolate with simultaneous resistance to the four antimicrobials of interest. Laboratory files were reviewed to identify MDR-PA isolates. Whenever more than one positive culture from a single patient was verified, only the first result was included in the study. The incidence of MDR-PA was expressed as the number of isolates per 1,000 patients-day.

Data from antimicrobial use and incidence of MDR-PA were submitted to statistical analysis using SPSS software version 15.0 (CSPSS inc). Linear regression models were used: both univariate, for each antimicrobial individually; and multivariate, entering data from all antimicrobials simultaneously. A p-value of $<0.05$ was set as the limit for statistical significance. The regression model was also used to detect possible outliers; i.e., units that did not follow the pattern of correlation. In this study, an outlier was defined as a unit for which the MDR-PA incidence value differed from the model expected value by more than three standard deviations.

\section{Ethical}

The study was fully approved by the local Ethics in Research Committee.

\section{RESULTS}

During the study period, 350 patients from the 18 hospital units for adults had at least one clinical culture positive for P. aeruginosa. The proportion of subjects with multidrug-resistant strains was $23.1 \%$. That meant a general incidence of MDR-PA of 0.48 per 1,000 patients-day.

Aggregate data on antimicrobial consumption study units (measured in DDD/1,000 patients-day) were: amikacin, 24.12; ciprofloxacin, 27.09; ceftazidime, 7.30 and imipenem, 15.81. Table 1 presents the use and resistance data from individual units.

In the univariate analysis, a significant correlation between consumption and MDR-PA incidence was verified for all four antimicrobials studied (Figure $\mathbf{1}$ and Table 2). However, in the multivariate model, only the consumption of imipenem was significantly associated with the incidence of resistant strains (Table 2). Of note, no outliers were detected.

TABLE 1 - Use of antipseudomonal antibiotics and incidence of multidrug-resistant Pseudomonas aeruginosa among the 18 study units.

\begin{tabular}{|c|c|c|c|c|c|c|}
\hline Hospital unit & Patients-day & \multicolumn{4}{|c|}{ Use of antimicrobials* } & MDR-PA incidence** \\
\hline Medical specialties \# 1 & 11,247 & 14.40 & 15.07 & 9.78 & 18.67 & 0.71 \\
\hline Medical specialties \#3 & 14,317 & 14.46 & 33.63 & 20.26 & 30.38 & 0.42 \\
\hline Infectious diseases & 9,020 & 12.31 & 17.29 & 6.43 & 16.96 & 0.55 \\
\hline Neurology and neurologic surgery & 10,550 & 11.37 & 6.68 & 7.39 & 7.54 & 0.57 \\
\hline Orthopedics and plastic surgery & 13,789 & 51.35 & 25.78 & 4.64 & 6.20 & 0.12 \\
\hline Cardiac and thoracic surgery & 10,202 & 12.35 & 13.82 & 1.76 & 7.94 & 0.1 \\
\hline Vascular surgery & 8,979 & 25.73 & 38.92 & 6.01 & 18.71 & 0.78 \\
\hline Ophthalmology and otorhinolaryngology & 6,647 & 16.70 & 23.24 & 1.50 & 0.23 & 0.00 \\
\hline Urology & 7,158 & 31.85 & 64.54 & 10.34 & 41.07 & 0.42 \\
\hline Medical-surgical ICU \# 1 & 4,964 & 48.35 & 34.15 & 8.46 & 53.79 & 1.81 \\
\hline Medical-surgical ICU \#2 & 6,268 & 71.31 & 112.72 & 23.93 & 59.11 & 2.39 \\
\hline Coronary ICU & 2,582 & 2.32 & 11.04 & 3.10 & 1.74 & 0.00 \\
\hline Private patient's ward & 4,277 & 28.06 & 30.51 & 9.82 & 17.18 & 0.70 \\
\hline
\end{tabular}

MDR-PA: multidrug-resistant Pseudomonas aeruginosa, ICU: intensive care unit.

${ }^{*}$ in number of defined daily doses (DDD) per 1,000 patients-day, ${ }^{* *}$ positive cultures per 1,000 patients-day. 
TABLE 2 - Results from linear regression analysis for the correlation of antimicrobial use and the incidence of multidrug-resistant Pseudomonas aeruginosa.

\begin{tabular}{|c|c|c|c|c|}
\hline \multirow[b]{2}{*}{ Antimicrobial } & \multicolumn{2}{|l|}{ Univariate analysis } & \multicolumn{2}{|l|}{ Multivariate analysis } \\
\hline & correlation coefficient & $\mathrm{p}$ & correlation coefficient & $\mathrm{p}$ \\
\hline Amikacin & $0.73^{*}$ & $0.001^{*}$ & 0.31 & 0.14 \\
\hline Ciprofloxacin & $0.71^{*}$ & $0.001^{*}$ & -0.13 & 0.57 \\
\hline Ceftazidime & $0.61^{*}$ & $0.007^{*}$ & 0.16 & 0.31 \\
\hline Imipenem & $0.87^{*}$ & $<0.001^{*}$ & $0.67^{*}$ & $0.01^{*}$ \\
\hline
\end{tabular}

*significant results.
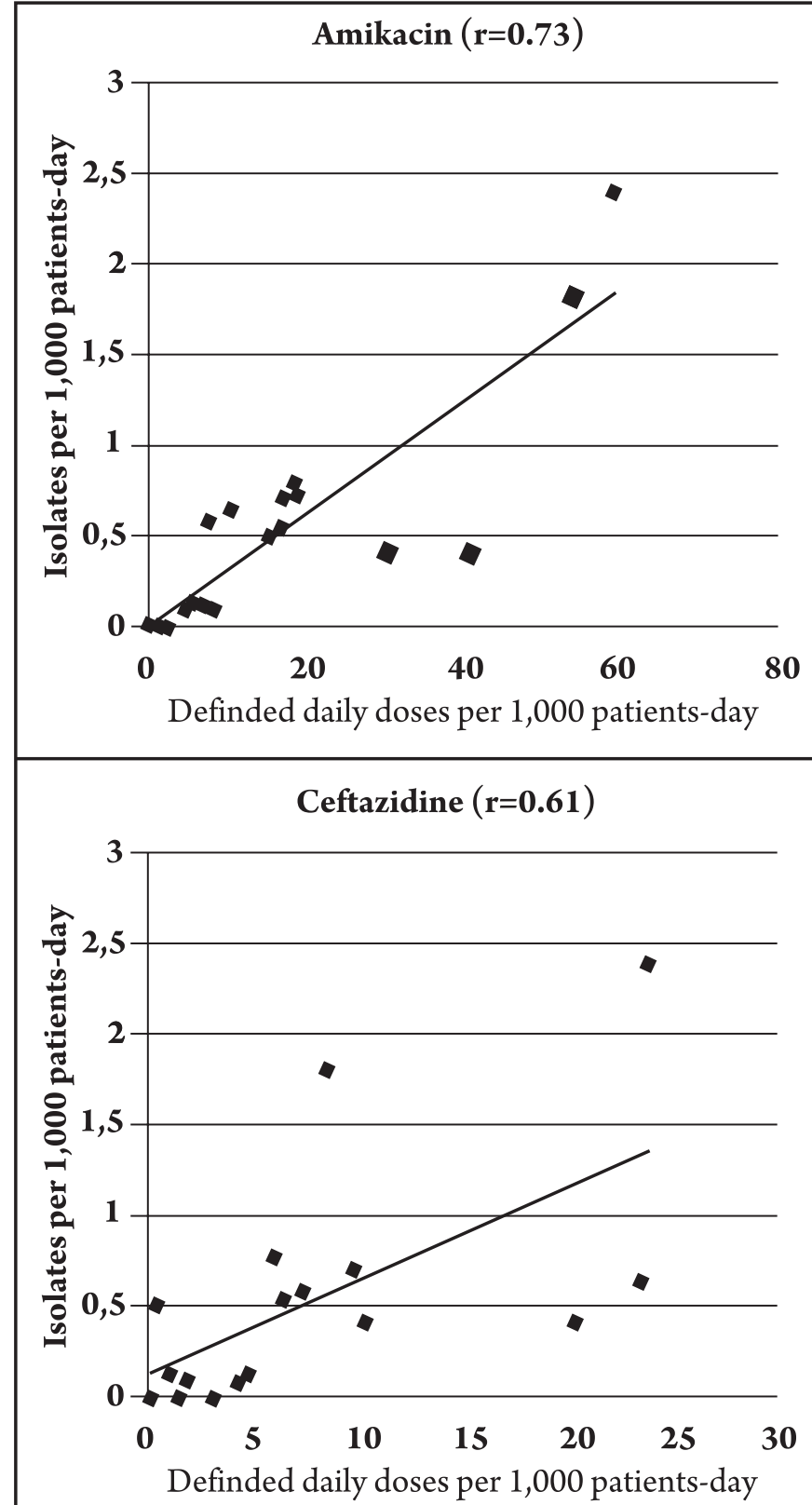

FIGURE 1 - Correlation of antimicrobial use and incidence of multidrug-resistant Pseudomonas aeruginosa among 18 hospital units for adult patients.

\section{DISCUSSION}

The advantages and limitations of ecological studies in epidemiology have been extensively studied ${ }^{10,11}$. This design is frequently used in public health, when data are more readily available for populations than for individuals. On the other hand, there is a risk that that aggregate data do not correctly reflect the distribution
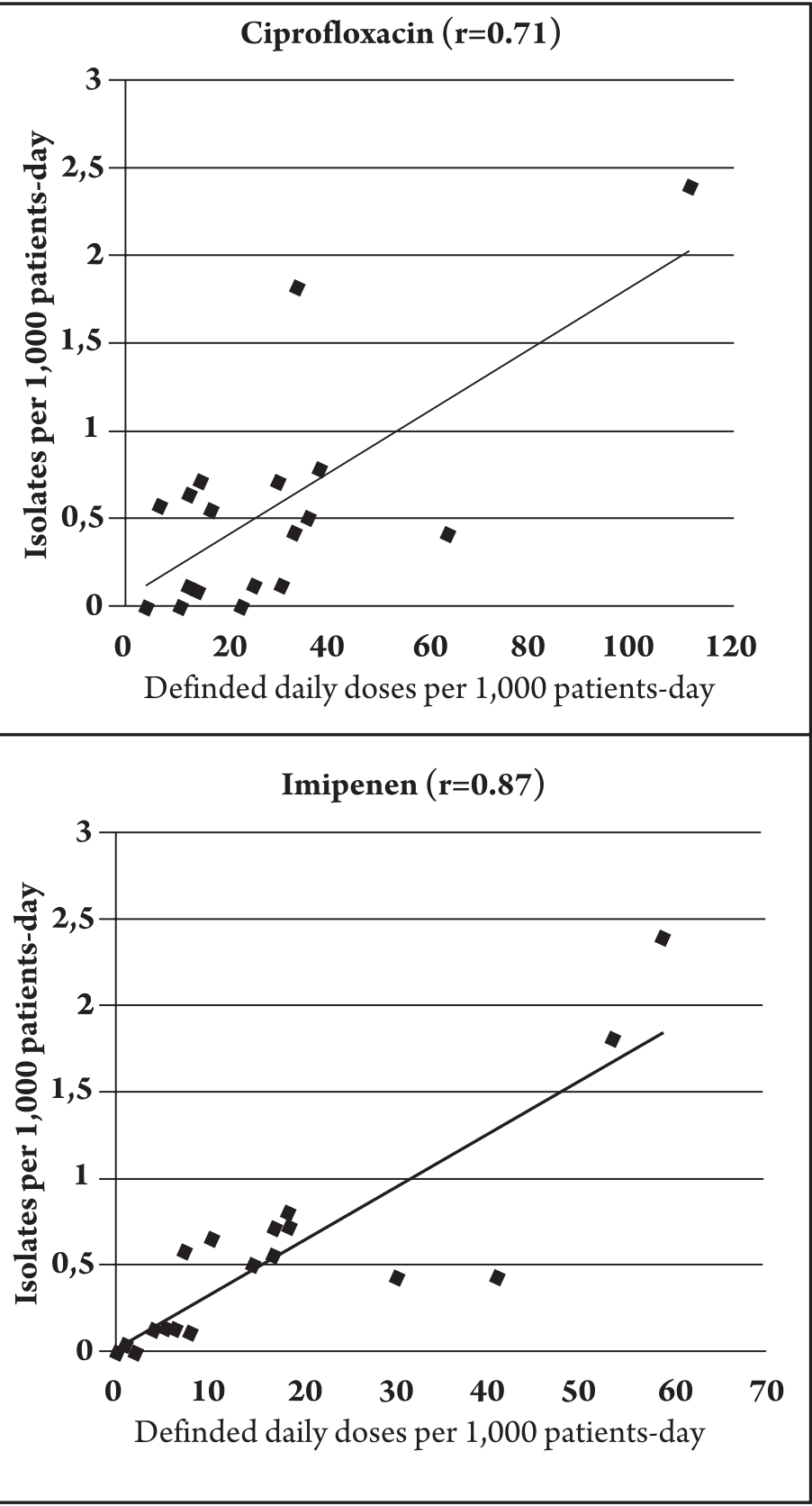

of exposure and effects within individuals. This limitation has been termed ecological fallacy or aggregate bias.

However, ecological fallacy does not invalidate the analysis of aggregate data. Szklo \& Nieto emphasize special circumstances in which ecological designs may identify associations that are missed in individual base studies ${ }^{12}$. This occurs when the variation of exposure within populations is greater than within individuals 
from the same population or when implications from intervention strategies are essentially collective. Additionally, ecological designs are suitable for studies of transmission of infectious agents, in which herd immunity plays an important epidemiological role.

The last assumption is of particular interest. Herd immunity occurs when vaccination of a portion of the population provides protection to unvaccinated people. Interestingly, Lipsitch and Samore state that the effect of antimicrobials in the spread of multidrug-resistant pathogens may follow a similar pattern, only in the opposite direction ${ }^{7}$. This means that when a portion of the population uses an antimicrobial and is colonized or infected by a multidrug-resistant agent, increased risk of acquiring this agent among individuals who did not receive the antimicrobial also exists. This is due to intensive cross-transmission of microorganisms within hospital units. We could call this phenomenon herd susceptibility.

The possible occurrence of herd susceptibility to MDR-PA among patients treated with antipseudomonal drugs argues for the validity of this study. Moreover, the findings are quite similar to those reported in case-control studies. This is especially true for the common finding of imipenem use as a risk factor for the acquisition of imipenem-resistant P. aeruginosa strains ${ }^{5,6}$. Strong correlations between amikacin use and resistance must be emphasized, since they contradict the traditional belief that combination therapy (beta-lactams plus aminoglycosides) prevents resistance ${ }^{6,13}$. On the other hand, ceftazidime seems to play a lesser role than imipenem in the selection of resistant strains $s^{6,14}$.

Two limitations of the present study must be stressed. First, the analysis does not include other antimicrobials with antipseudomonal activity (such as levofloxacin and cefepime) or drugs that, though not active against $P$. aeruginosa, have been reported to facilitate the spread of MDR-PA (such as vancomycin). This was a deliberate choice, since the performance of regression models with many variables (with possible interactions and colinearity) could reduce the sensitivity of the analysis. We restricted our interest to the four study drugs, because these are routinely included in susceptibility tests for all clinical cultures in our hospital.

The other limitation may arise from not including data on patient severity or invasive procedures in the analysis. This was beyond the scope of the study. Obviously, the higher incidence of MDR-PA in intensive care units may be partly related to factors other than the use of antimicrobials ${ }^{15}$.

In conclusion, the study provides a populational perspective concerning the relation between antimicrobial use and the incidence of MDR-PA in a teaching hospital. The results are in agreement with findings from observational studies that focus on individual exposures and outcomes. A role for antipseudomonal agents, particularly imipenem, in the selection of resistant strains is strongly suggested. This reinforces the importance of including antimicrobial stewardship among infection control practices that aim to reduce the spread of MDR-PA in acute care hospitals.

\section{CONFLICT OF INTEREST}

The authors declare that there is no conflict of interest.

\section{REFERENCES}

1. Hidron AI, Edwards JR, Patel J, Horan TC, Sievert TM, Pollock DA, et al NHSN annual update: antimicrobial-resistant pathogens associated with healthcare-associated infections: annual summary of data reported to the National Healthcare Safety Network at the Centers for Disease Control and Prevention, 2006-2007. Infect Control Hosp Epidemiol 2008; 29: 996-1011.

2. Ribeiro J, Mendes RE, Domingos R, França E, Silbert S, Jones RN, et al. Microbiological and epidemiological characterization of imipenem-resistant
Pseudomonas aeruginosa strains from a Brazilian tertiary hospital: report from the SENTRY Antimicrobial Surveillance Program. J Chemother 2006; 18:461-467.

3. McGowan Jr JE. Resistance in nonfermenting gram-negative bacteria: multidrug resistance to the maximum. Am J Med 2006; 119(suppl 1):S29-36.

4. Harris AD, Smith D, Johnson JA, Bradham DD, Roghmann MC. Risk factors for imipenem-resistant Pseudomonas aeruginosa among hospitalized patients. Clin Infect Dis 2002; 34:340-345.

5. Zavascki AP, Cruz RP, Goldani LZ. Risk factors for imipenem-resistant Pseudomonas aeruginosa: a comparative analysis of two case-control studies in hospitalized patients. J Hosp Infect 2005; 59:96-101.

6. Fortaleza CM, Freire MP, Filho D de C, de Carvalho Ramos M. Risk factors for recovery of imipenem-or ceftazidime-resistant Pseudomonas aeruginosa among patients admitted to a teaching hospital in Brazil. Infect Control Hosp Epidemiol 2006; 27:901-906.

7. Lipsitch M, Samore MH. Antimicrobial use and antimicrobial resistance: a population perspective. Emerg Infect Dis 2002; 8:347-354.

8. Natsch S, Hekster YA, de Jong R, Heerdink ER, Herings RM, van der Meer JW. Application of the ATC/DDD methodology to monitor antibiotic drug use. Eur J Clin Microbiol Infect Dis 1998; 17: 20-24.

9. Clinical and Laboratory Standards Institute. Performance standards for antimicrobial disk susceptibility tests; approved standard, $8^{\text {th }}$ ed. Pennsylvania: CLSI; 2003.

10. Morgenstern H. Ecologic studies in epidemiology: concepts, principles and methods. Annu Rev Public Health 1995; 16:61-81.

11. Wakefield J. Ecologic studies revisited. Annu Rev Public Health 2008; 29:75-90.

12. Szklo M, Nieto FJ. Epidemiology - beyond the basics. Gaitheresburg: Aspen Publishers; 2000.

13. El Amari, EB Chamot E, Auckenthaler R, Pechere JC, Van Delden C. Influence of previous exposure to antibiotic on the susceptibility patterns of Pseudomonas aeruginosa bacteremic isolates. Clin Infect Dis 2001; 33:1859-1864.

14. Carmeli Y, Troillet N, Eliopoulos GM, Samore MH. Emergence of antibioticresistant Pseudomonas aeruginosa: comparison of risks associated with different antipseudomonal agents. Antimicrob Agents Chemother 1999; 43:1379-1382.

15. Clark NM, Patterson J, Lynch JP $3^{\text {rd }}$. Antimicrobial resistance among gram-negative organisms in the intensive care unit. Curr Opin Crit Care 2003; 9: 413-423. 